\title{
As Principais Abordagens da Temática Meio Ambiente no Ensino de Química
}

Danilo Lima Dantas* (Graduando em Química na Universidade Federal de Campina Grande - UFCG);

Aline Priscila de França Silva (Graduanda em Química na Universidade Federal de Campina Grande UFCG);

Felipe Antonio da Costa Santos (Licenciado em Química pela Universidade Federal de Campina Grande - UFCG);

J osé Carlos Oliveira Santos (Professor da UABQ/CES na Universidade Federal de Campina Grande -

UFCG)

*E-mail: danilold.15@gmail.com

Resumo: Os problemas ambientais são um paradoxo atual para todos os ramos da educação ambiental, tentando reverter os graves danos ambientais que eclodiram dentro dos últimos 200 anos, dentro do universo da Química Ambiental surge um novo ramo científico que se denomina a Química Verde cujo intuito é o desenvolvimento e a aplicação de produtos e processos químicos para reduzir ou para eliminar o uso e a geração de substâncias perigosas. O presente trabalho teve como objetivo retratar o desenvolvimento da temática meio ambiente dentro do ensino de química através de uma retrospectiva através de artigos, relatando o desenvolvimento dessa temática no ensino através de uma análise quantitativa e percentual do número de trabalhos aceitos no Congresso Brasileiro de Química (CBQ). Outro viés que também foi salientado por meio deste trabalho, foi analisar as diversas vertentes da química ambiental que estão sendo mais retratadas dentro do universo acadêmico. Os resultados demonstraram que a educação ambiental vem se tornando cada vez mais freqüentemente agregada a educação química, tendo em vista que no âmbito educacional se oportuniza ferramentas que viabilizem o uso sustentável da ciência.

Palavras-chave: Ensino de química; química ambiental; meio ambiente; contextualização.

Espaço reservado para organização do congresso. 


\section{I ntrodução}

A sociedade atual vem sofrendo graves problemas climáticos devido ao uso incorreto dos recursos naturais conjuntamente com o despejo de forma exacerbada de produtos químicos que geraram por sua vez danos aos ecossistemas e também eclodindo na destruição de grande parte da biodiversidade presente na Terra. Através dos entraves sociais que foram gerados com a crise ambiental práticas motivacionais tiveram o intuito de reeducar as futuras gerações, dando lhes conceitos primordiais de cidadania e modificando a situação catastrófica que se projetava com o excesso do uso dos recursos naturais de forma desordenada, que fora eclodido por sua vez pela falta de conhecimento da população em utilizar a sustentabilidade e suas práticas recorrentes para se reduzir o consumo de matéria natural e evitar a crescente contaminação dos ecossistemas, principalmente por resíduos industriais descartados inapropriadamente. Foi agregado na década de 60 o ensino ambiental dentro das grades curriculares das ciências, inicialmente. Segundo Bonfim: " a Educação Ambiental apresenta a possibilidade de ir além de uma simples conscientização, mas poderá alcançar patamares mais avançados, questionando tanto a maneira como os homens estão reproduzindo suas vidas, como forma de se analisar a relação de natureza e capitalismo” (DYONISIO e MESSEDER apud BONFIM, 2009).

No ensino de química a temática meio ambiente se agregou de forma extremamente expressiva e os profissionais de vários ramos dessa ciência foram criando diversas pesquisas dentro desse universo, e com isso foi criado um novo ramo, a Química Ambiental. A Sociedade Brasileira de Química (2011) ressalta que essa nova vertente estuda: “[...] os processos químicos que ocorrem na natureza, sejam eles naturais ou ainda causados pelo homem, e que comprometem a saúde humana e a saúde do planeta como um todo (DYONISIO e MESSEDER apud SBQ, 2011).

Dentro do universo da educação química, o ensino ambiental conseguiu desenvolver novas ferramentas, explicando os processos de poluição e degradação da natureza e também conseguiu desenvolver novos produtos que conseguiram unir eficácia e sustentabilidade em sua formulação.

Ao se falar em Meio Ambiente pode se ver uma amplitude de leques de atuação, e é nessa diversidade de subdivisões do ensino ambiental que surge a interdisciplinaridade na educação. O que priorizou novas fórmulas de se aprender que quebram paradigmas disciplinares.

Diante do constatado, foi percebido a ampla atuação que a química ambiental possui dentro das principais inovações e práticas sociais presentes nas comunidades atuais. Devido a isso, se tornou viável investigar a presença da temática meio ambiente dentro das publicações aceitas do Congresso Brasileiro de Química (CBQ) e elencar as suas principais vertentes.

\section{Metodologia}

O trabalho se conceitua como uma revisão bibliográfica, que se constituiu da seguinte forma. Inicialmente foram feitas coletas nos Anais do Congresso Brasileiro de Química (CBQ), dentro do período de (2007- 2013) com a temática meio ambiente e ensino de química.

Os dados obtidos passaram por uma análise quantitativa de publicação por cada ano, e com isso foi comparado à frequência desse tema dentro do total de publicações. Após isso foi feita uma análise dos subtemas encontrados nos artigos e demonstrados através de macro áreas, que foram: saúde, que incluiu trabalhos que falam da utilização de atividades práticas relacionado a algum elemento ambiental e sua correlação com o bem estar humano; Educação Verde, que esta ligado a práticas químicas relacionadas a sustentabilidade; biomassa, que se relacionam aos trabalhos que abordam especificamente a criação de novas abordagens energéticas que ajudem o meio ambiente; estudo avaliativo, que ressaltam os trabalhos que falam sobre a proporção de determinada substância no meio ambiente e sua análise química e funcional e problemas ambientais que esta incluso os trabalhos que utilizam algum dano ambiental atual e suas possíveis soluções.

\section{Resultados e Discussão}

\subsection{As projeções da temática meio ambiente dentro do ensino de química}

A temática meio ambiente sempre foi uma área de extrema importância dentro do ensino, que para conseguir o destaque que possui dentro da humanidade e educação passou por um processo gradativo de desenvolvimento dentro da sociedade e consequentemente educacional, geradas pela necessidade 
da humanidade corrigir sua interação exacerbada com o meio ambiente, iniciada principalmente na Revolução Industrial. Pelegrini diz que: A constituição industrial do século XVIII agregada aos processos de modernização ocasionou desajustes econômicos e sociais (PELEGRINI e VLACH, 2011), esses desajustes sociais são demonstrados de forma mais drástica no avanço do meio tecnológico sobre o meio natural, e com isso gerando problemas climáticos e ambientais, "ocasionando por sua o esgotamento ou inviabilização dos recursos que são essenciais para a sobrevivência”' (RUA e SOUZA, 2011).

Vendo a necessidade de se reeducar as futuras gerações e modificar a situação catastrófica que se projetava com o excesso do uso dos recursos naturais de forma desordenada e com a crescente contaminação dos recursos naturais por resíduos industriais principalmente, foi agregado por volta de 1960 o ensino ambiental dentro das grades curriculares das ciências. Segundo Bonfim "a Educação Ambiental apresenta a possibilidade de ir além de uma simples conscientização, mas poderá alcançar patamares mais avançados, questionando tanto a maneira como os homens estão reproduzindo suas vidas, como forma de se analisar a relação de natureza e capitalismo" (DYONISIO e MESSEDER apud BONFIM, 2009).

A Educação Ambiental foi uma forma que deu ao ensino mais uma ferramenta de elucidar os problemas do cotidiano com a aplicação prática dos assuntos, despertando o senso de pesquisador de muitos indivíduos. Dias diz em sua obra que: “[...] O Ensino Ambiental caracteriza se como um processo permanente no qual os indivíduos e a comunidade tomam consciência do seu meio ambiente e adquirem conhecimentos, valores, habilidades, experiências e determinação que os tornem aptos a agir e resolver problemas ambientais, presentes e futuros. (RUA e SOUZA apud DIAS, 1992).

Vale salientar que não foi apenas a criação de novos ramos dentro do universo químico que eclodiram com o desenvolvimento da temática meio ambiente dentro dessa ciência, mas também a interação entre Química e meio ambiente, vem auxiliando de forma positiva no processo de ensino aprendizagem. De acordo com Marques e Lindeman (2000), a discussão dos Temas Sociais articulados ao Ensino de Química é uma possibilidade para auxiliar na compreensão dos problemas em que a sociedade se encontra imersa (MARQUES e LINDEMAN, 2000). Também cabe com a integração entre a Química e Meio Ambiente quebrar paradigmas errôneos de pensamento que muitas vezes são projetados pelo senso comum em tratar a Química como má.

\subsection{Análise bibliográfica dos anais do CBQ}

Através dos dados obtidos nas Tabelas 1 e 2 pode se perceber que o ensino ambiental teve um crescimento significativo tanto quantitativo quanto percentual. É importante salientar que em 2011 houve um crescimento percentual mais expressivo devido provavelmente a grande difusão de eventos sustentáveis, além da implantação pela ONU do ano internacional das florestas, 2012 teve a Rio + 20, que foi um evento de grande difusão dentro do país e 2013 por sua vez pode se perceber um maior valor quantitativo e um número alto de trabalhos publicados devido as iniciativas do MEC em 2013 ao incentivar dentro do plano de ensino a incrementação da grade curricular com semanas ambientais que visassem pesquisas e socializações sobre práticas de preservação ecológica, o que fez consequentemente aumentar a pesquisa sobre esse tema e também o número de trabalhos.

Tabela 1 - Trabalhos com a temática meio ambiente aceitos no Congresso Brasileiro de Química no período de 2007-2013.

\begin{tabular}{c|c|c|c}
\hline Edição CBQ & $\begin{array}{c}\text { Número de artigos } \\
\text { totais }\end{array}$ & $\begin{array}{c}\text { Número de artigos } \\
\text { encontrados com a } \\
\text { temática }\end{array}$ & Valor percentual \\
\hline 2007 & 614 & 19 & $3,09 \%$ \\
\hline 2008 & 585 & 23 & $3,91 \%$ \\
\hline 2009 & 462 & 21 & $4,55 \%$ \\
\hline 2010 & 408 & 21 & $5,15 \%$ \\
\hline 2011 & 712 & 44 & $6,18 \%$ \\
\hline 2012 & 1068 & 44 & $4,12 \%$ \\
\hline 2013 & 1167 & 57 & $4,89 \%$ \\
\hline
\end{tabular}


Na Tabela 2, foi percebido as principais vertentes relacionadas à química e meio ambiente nos trabalhos aceitos da CBQ no período de 2007 até 2013. Foi visto a presença em grande escala de determinados subtemas como biomassa, onde se ressalta a utilização de fontes de energia limpas que evitem o dano ao meio ambiente e que suas reações foram utilizadas dentro da educação como forma de fomentar novas ideias, como demonstrados nos trabalhos de Lobo et al. (2007) e Pinto et al. (2007), presentes na Tabela 2 subtema biomassa.

Tabela 2 - Análise das macro-áreas presentes no CBQ sobre a temática Meio Ambiente no Ensino de Química no período 2007-2013.

\begin{tabular}{c|c|c}
\hline Temática & Quantitativo & Valor percentual \\
\hline Saúde & 13 & $5,69 \%$ \\
\hline Conscientização ecológica & 92 & $40,17 \%$ \\
\hline biomassa & 20 & $8,73 \%$ \\
\hline Estudo Avaliativo & 66 & $28,82 \%$ \\
\hline Problema Ambiental & 38 & $16,59 \%$ \\
\hline
\end{tabular}

Outra proposta temática comum nos trabalhos foi a de analisar os problemas ambientais e utilizar as reações químicas como subsidio para uma aula interativa, como foi demonstrado no trabalho de Musyetetal (2009) e Tavares et al. (2009),que relacionaram a análise dos problemas ambientais como subsidio para se interligar problemas do cotidiano a assuntos como ligação covalente e relacionarem substâncias liberadas por automóveis e outros meios de transporte com o aquecimento global e a chuva ácida. No subtema saúde houve a demonstração em aulas de substâncias presentes em determinados fármacos hospitalares, como dito nos trabalhos de Souza et al. (2007) e Queiróz (2011).

Outras propostas de subtemas que apresentaram uma maior interação com o ensino ambiental e química foram estudos avaliativos que analisaram a presença de determinadas substâncias em meio naturais, exemplo disso foi o trabalho de Pereira (2011) feito com alunos que apresentaram a análise quantitativa da presença de metano no lixo de Costa Neto (2011) que analisou com alunos a presença de óxido de nitrogênio presente na água.

Contudo, o subtema com maior proporção dentro do Congresso Nacional de Química dessa amostra de sete anos foi o subtema conscientização ecológica, que ressaltou a importância da preservação ambiental utilizando produtos menos agressivos, como destacado nos trabalhos de Ramos (2012) e de Lima (2012).

\section{Considerações Finais}

Diante do que foi constatado através desta analise bibliográfica, pode se perceber que a educação ambiental é um tema de extrema importância dentro do ensino, não apenas pelo viés social, mas também pela contextualização com os assuntos que são tradicionais do ensino de química. A educação ambiental por sua vez vem se tornando cada vez mais frequentemente agregada a educação química, pois no âmbito educacional se oportuniza ferramentas que viabilizem o uso sustentável da ciência.

Além disso, enfatiza se que o apoio das mídias e das campanhas sociais que visam demonstrar a importância de se preservar e também demonstram os danos ambientais que a produção exacerbada e desregrada vem causando aos habitats naturais vem sido de suma importância para se aumentar a produção de artigos com temáticas ambientais, além de impulsionar maiores números de pesquisas que instigam a reduzir o impacto humano nos ecossistemas e com isso melhorar a qualidade de vida. 


\section{The Main Theme of Environment Approaches in Chemistry Teaching}

Albstract: Environmental problems are a current paradox to all branches of environmental education, trying to reverse the severe environmental damage that erupted within the past 200 years, within the Environmental Chemistry universe there is a new field of science that is called the Green Chemistry whose purpose is the development and application of chemical products and processes to reduce or to eliminate the use and generation of hazardous substances. This study aimed to portray the development of thematic environment within the chemistry teaching through a retrospective through articles, reporting the development of this issue in education through a quantitative analysis and percentage of the number of papers accepted at the Brazilian Chemical Congress (CBQ). Another point which was also highlighted through this work was to analyze the various aspects of environmental chemistry being more portrayed within the academic world. The results showed that environmental education is becoming increasingly frequently aggregate chemistry education, considering that in the education sector provides an opportunity to tools that enable sustainable use of science.

Keywords:Chemistry education; environmental chemistry; environment; contextualization.

\section{Referências bibliográficas}

ALVIM, D. S.; CORREIA, C. S. C.; GATTI, L. V.; BASSO, L. F.; MILLER, J. B.; ROCHA, H. R.; GLOOR, M. Estudo do fluxo de n2o sobre a bacia amazônica. In CBQ. Disponível em: http://www.abq.org.br/cbq/2011/trabalhos/5/5-208-5117.htm. Acesso em: 02/09/2014

COSTA NETO, P. V. Aplicação de análise de componentes principais (pca) na identificação simulada de adulteração de óleo diesel In CBQ. disponível em:http://www.abq.org.br/cbq/2011/trabalhos/5/5325-11260.htm acesso em 02/09/2014

DIONYSIO, R. B.; MESSEDER, J. C. Química Ambiental x Educação Ambiental: o que os professores de Química do Ensino Médio. In Anais do3 Congresso Nacional de Ciências da Saúde e do Meio Ambiente. Niterói-RJ, 2012

FERREIRA, A. S.; VIANNA, C. A. F. J.; BATISTA, R. G. S.; DILL, T. F.; FERREIRA, L. S. O lixo como tema para uma investigação em projetos de educação ambiental. In CBQ. Disponível em: http://www.abq.org.br/cbq/2011/trabalhos/6/6-582-536.htm. Acesso em: 02/09/2014.

JÚNIOR, G. J.; ALVES, C. P. A proteção ambiental e a interdisciplinaridade: uma aproximação entre o Direito Ambiental e a Química Ambiental. Cadernos de Ciências Sociais Aplicadas .Vitória da Conquista-BA. n.12 . p. 53-69 . 2011

LEAL, A. L.; MARQUES, C. A. O Conhecimento Químico e a Questão Ambiental na Formação Docente. Química Nova na Escola. № 29, 2008

LIMA, M. M. G.; SILVA, E. C.; RODRIGUES, E. N. B.; SANTOS, C. B. R. Água: uma abordagem de química no ensino médio. In CBQ. Disponível em: http://www.abq.org.br/cbq/2011/trabalhos/6/6262-651.htm. Acesso em: 02/09/2014.

LINDEMANN, R. H.; MARQUES, C. A.Contextualização e Educação Ambiental no Ensino de Química: As I mplicações na Educação do Campo. In Anais do Congresso Nacional de Pesquisa em Educação em Ciências. Florianópolis, 2000

LOBO, V. S.; MULLER, A. P.; EGGERS, C.; CICHOSKI, C.; REMOR, E.; LEDUR, F.; MARCHIOTTI, G.; SOUZA, G.; BRUXEK, R. L. Estudo dos impactos ambientais gerados pelos combustíveis automobilísticos pelos acadêmicos do curso tecnologia em gerenciamento ambiental da utfpr/campus 
medianeira. In CBQ. Disponível em: http://www.abq.org.br/cbq/2007/trabalhos/5/5-555-688.htm. Acesso: 02/09/2014.

MUSY, R. C.; TAKASE, I.; FERREIRA, K. C. R. Discutindo a chuva ácida. In CBQ. Disponível em: http://www.abq.org.br/cbq/2009/trabalhos/6/6-312-6578.htm. Acesso em: 02/09/2014.

PELLEGRINI, D. F.; VLACH, V. R. F. As múltiplas dimensões da Educação Ambiental: por uma ampliação da abordagem. Sociedade e natureza. Uberlândia, ano 23 n. 2, 187-196, 2011

PEREIRA,V. B. Análise da contaminação por metais-traço no solo próximo ao complexo industrial de duque de caxias/rj, Brasil. In CBQ. Disponível em: http://www.abq.org.br/cbq/2011/trabalhos/5/index.html. Acesso em 02/09/2014

PINTO, F.; MOURA, J.; FERREIRA, S.; SANTOS, E.; Estudo comparativo entre as formas de energias convencionais e não convencionais. In CBQ. Disponível em: http://www.abq.org.br/cbq/2007/ trabalhos/5/5-5-44.htm. Acesso: 02/09/2014.

QUEI ROZ, M.T.A; QUEIROZ, C. A; ALÍPIO, V. C; COELHO, C. D. P; FERNANDES, C. Ação Ambiental no Sistema Único de Saúde. In CBQ. Disponível em: http://www.abq.org.br/cbq/2011/trabalhos/5/5-75011587.htm. Acesso em 02/09/2014.

REGO, P. P.A.'LIMA, F. A. A.; FERNANDES, E. L.; DIAS, I. J. M. Extração e saponificação do óleo de mamona. In CBQ. Disponível em: http://www.abq.org.br/cbq/2011/trabalhos/6/6-689-11192.htm. Acesso em: 02/09/2014.

RUA, E. R.; SOUZA, P. S. A. Educação Ambiental em uma Abordagem Interdisciplinar e Contextualizada por meio das Disciplinas Química e Estudos Regionais. Química Nova na Escola. Vol. 32, $\mathrm{N}^{\circ} 2,2010$.

SOUZA, W. F. L; SILVA, N. F; MACHADO, G. G. M; WINTER, L. S. Aditivos de chumbo em tubulações de pvc: risco de impactos a saúde e ao meio ambiente ou passivo ambiental?. In CBQ. Disponível em: http://www.abq.org.br/cbq/2007/trabalhos/5/5-728-861.htm. Acesso em:03/09/2014.

SANTOS, J. A.; JÚNIOR, L. P. C.; BEJ ARANO, N.R. A Interdisciplinaridade no Ensino de Química: Uma análise dos artigos publicados na revista Química Nova na Escola entre 1995 e 2010. Revista de Educação, Ciências e Matemática v.1 n.1, 2011

TAVARES, L. C.; BARRA, I. M. M.; SILVA, B. M. P.; A contextualização do aquecimento global nos conteúdos de química no ensino médio. In CBQ. Disponível em: http://www.abq.org.br/cbq/2009/trabalhos/6/6-449-6513.htm. Acesso em: 02/09/2014. 